\author{
Stefan J. Borgwardt \\ Paolo Fusar-Poli \\ Ernst-Wilhelm Radue \\ Anita Riecher-Rössler
}

\section{Insular pathology in the at-risk mental state}

Received: 13 November 2007

Accepted: 26 November 2007

Published online: 8 March 2008

Sirs: We would like to contribute on the article by Saze et al. [5] summarizing in a timely review and region-of-interest study the findings of insular volumes in patients with schizophrenia. They observed that total insular gray matter volumes were significantly reduced in patients with schizophrenia compared to healthy controls. They also suggested that insular abnormalities in schizophrenia would include anterior as well as posterior parts, with most pronounced reductions in the right posterior insula.

Despite a large body of neuroimaging studies in schizophrenia showing volumetric insular abnormalities, it is still unclear whether this is due to abnormal brain development or neurodegeneration. Therefore, it seems fundamental for the understanding of the pathogenesis of insular pathology to establish the timing

S. J. Borgwardt $(\bowtie) \cdot$ A. Riecher-Rössler Psychiatric Outpatient Department University Hospital Basel

Basel, Switzerland

E.-W. Radue S. J. Borgwardt Neuroradiological Department

University Hospital Basel

Basel, Switzerland

ઠ゙ P. Fusar-Poli · S. J. Borgwardt

Institute of Psychiatry

King's College London

London, UK of the occurrence of these volumetric abnormalities, particularly whether they are already present prior to a first psychotic episode. However, very little is known about the nature of insular volume abnormalities in individuals in the prodromal phase of developing psychosis. In very recent studies of subjects at high-risk of developing psychosis [4] we compared grey matter volumes of subjects with an at-risk mental state (ARMS) with patients with first-episode psychosis and healthy controls $[1,2]$.

When we focus specifically on the insular abnormalities, the ARMS (independent of subsequent clinical outcome) group showed areas of reduced grey matter volume in the left insula compared to healthy controls. However, the ARMS group was heterogenous including both, patients who later developed psychosis and those who did not. Within the ARMS group, those subjects who later developed psychosis had even less grey matter in the right insula than subjects who did not. That finding is suggestive that insular volume abnormalities associated with psychosis are already present before the first episode of psychosis. These abnormalities may therefore reflect abnormal developmental processes and may be related to an increased vulnerability to psychosis. Also, Pantelis et al. [3], using a voxel-based approach, found that subjects with 'prodromal' symptoms and an ARMS who later became psychotic had smaller right insular volumes than those who did not.

To further clarify the nature of the insular volumes in the ARMS group who subsequently developed psychosis we then compared this subgroup with healthy controls and patients with first-episode psychosis directly. Compared with healthy controls, the ARMS group who subsequently developed psychosis showed smaller right insular volume. No differences in insular volumes were, however, found between the ARMS who subsequently developed psychosis and patients with first-episode psychosis.

The results of these studies of subjects at high-risk of developing psychosis indicate that insular abnormalities are already present before the transition to psychosis. The early abnormalities may reflect developmental or later maturational processes in adolescence and early adulthood and may be associated with an increased vulnerability to psychosis. Additional volumetric abnormalities in the insula within the ARMS group seem to be particularly associated with a subsequent development of psychosis. These brain areas may be particularly informative to a better understanding of the underlying neurobiology of the progression to psychosis. Further longitudinal neuroimaging studies of subjects with an ARMS should clarify the significance of these findings.

\section{References}

1. Borgwardt SJ, Riecher-Rössler A, Dazzan $\mathrm{P}$, Chitnis X, Aston J, Drewe M, Gschwandtner U, Haller S, Pflüger M, Rechsteiner E, Semenin V, Stieglitz RD, Radü EW, McGuire PK (2007) Regional grey matter abnormalities in the at risk mental state. Biol Psychiatry 61:1148-1156

2. Borgwardt SJ, McGuire PK, Aston J, Berger G, Dazzan P, Gschwandtner U, Pflüger M, Radü EW, Riecher-Rössler A (2007) Structural brain abnormlities in individuals with an at risk mental state who later develop psychosis. Br J Psychiatry 191:S69-S75

3. Pantelis C, Velakoulis D, McGorry PD, Wood SJ, Suckling J, Phillips LJ, Yung AR, Bullmore ET, Brewer W, Soulsby B, Desmond P, McGuire PK (2003) Neuro- 
anatomical abnormalities before and after onset of psychosis: a crosssectional and longitudinal MRI comparison. Lancet 361:281-288 4. Riecher-Rössler A, Gschwandtner U, Aston J, Borgwardt SJ, Drewe M, Fuhr P, Pflueger M, Radue EW, Schindler C,
Stieglitz RD (2007) The basel early detection of psychosis (FEPSY-) project-study design and first preliminary results. Acta Psychiatr Scand 115:114125
5. Saze T, Hirao K, Namiki C, Fukuyama H, Hayashi T, Murai T (2007) Insular volume reduction in schizophrenia. Eur Arch Psychiatry Clin Neurosci (in press) 